\title{
Recurrent Renal Pelvis Urothelial Carcinoma
}

National Cancer Institute

\section{Source}

National Cancer Institute. Recurrent Renal Pelvis Urothelial Carcinoma. NCI Thesaurus.

Code C150519.

Reemergence of renal pelvis urothelial carcinoma after a period of remission. 